\title{
What is new in IVF?
}

\section{Assisted reproductive technology has come a long way in 40 years}

Gabor T Kovacs MD, FRANZCOG, CREI Director

Monash IVF, Melbourne, VIC.

gkovacs@ monashivf.com

doi: $10.5694 / \mathrm{mjal} 4.01000$ $\mathrm{t}$ was just over 40 years ago that the first ever human pregnancy conceived through in-vitro fertilisation (IVF) was reported by the team from Melbourne. ${ }^{1}$ Unfortunately, the pregnancy only lasted for a few days and was what we would now call a biochemical pregnancy. It took another 5 years before Louise Brown, the world's first IVF child, was born in the United Kingdom on 25 July 1978, through the efforts of Patrick Steptoe and Bob Edwards, ${ }^{2}$ from their 102nd human embryo transfer. The British team had another birth, a less well known Alastair MacDonald, in January 1979, but the next 11 births occurred in Melbourne. ${ }^{3,4}$

Melbourne then became the international centre for IVF, not only converting the process to clinical treatment with a near $10 \%$ success rate by using stimulated cycles, ${ }^{5}$ but also pioneering world-firsts such as embryo freezing, ${ }^{6}$ egg donation, ${ }^{7}$ in-vitro maturation, ${ }^{8}$ blastocyst transfer ${ }^{9}$ and microinjection techniques - although the first human birth using microinjection was in Singapore. IVF was initially developed to overcome tubal disease before being adapted for use in women with unexplained subfertility. ${ }^{10}$ It also became the first effective treatment of male subfertility. ${ }^{11}$

Now, in 2014, IVF is practised in virtually every developed country. Well over five million babies have been born using the technology, from fresh and frozen embryo transfers.

There have been several changes to the practice of IVF in recent years.

For controlled ovarian hyperstimulation $(\mathrm{COH})$, the ability to predict response by measuring the anti-Müllerian hormone leve $\mathrm{l}^{12}$ has introduced greater precision. The application of gonadotropin-releasing hormone (GnRH) antagonist regimens has enabled shorter treatment cycles, and the availability of a long-acting follicle-stimulating hormone injection (corifollitropin alfa) has reduced the number of injections women have to administer. The risk of ovarian hyperstimulation syndrome, a potentially serious complication of $\mathrm{COH}$, has been almost eliminated by the ability to induce ovarian maturation by using a GnRH agonist in GnRH antagonist cycles.

The technique of oocyte collection has changed little since the introduction of the transvaginal ultrasoundguided technique in $1985,{ }^{13}$ although there has been movement from the operating theatre to procedure rooms in some centres.

There have also been major changes in the IVF laboratory. Although first reported in 1998, ${ }^{9}$ blastocyst transfer is now becoming the preferred method in leading IVF units around the world. This not only more closely matches the normal physiological process of conception, in which the embryo reaches the uterine cavity at the blastocyst stage (Day 5 after fertilisation) rather than the cleavage stage (Day 2 or 3), but it also allows a more scientific selection of the "best" embryo. Another major advance in the laboratory is the use of time-lapse photography of embryo development, which is being used to predict the embryo most likely to result in a successful pregnancy. The other change is the use of vitrification rather than slow freezing to preserve embryos, a technique that is better suited to blastocyst freezing, with survival rates exceeding $95 \%{ }^{14}$

There has been a move towards single embryo transfer (SET), in which Australia is again leading the world. While twins may be "cute" and seem like a good solution for childless couples, the perinatal morbidity and possible long-term medical and social problems of a multiple pregnancy ${ }^{15}$ mean that moving towards SET is the only responsible way to go. We have recently reported that the chance of taking home a healthy, full-term baby is higher if SET rather than double embryo transfer is performed. ${ }^{16}$

IVF has also been used in the area of pre-implantation genetic diagnosis for fertile couples who do not want to resort to antenatal diagnosis and possible termination of pregnancy when they are at risk of transmitting serious genetic conditions.

More recently, IVF technology has been applied to fertility preservation. This can be undertaken by freezing embryos, oocytes or ovarian tissue, with subsequent IVF treatment. The first successful Australian pregnancy after frozen ovarian tissue autotransplantation, which resulted in the birth of a healthy female baby, was reported in the Journal in 2013. ${ }^{17}$ This was followed by a set of IVF twins born after implanting ovarian tissue into the anterior abdominal wall. ${ }^{18}$

Another exciting development is the possibility of therapeutically improving the mitochondria within oocytes in the IVF laboratory. In the UK, the Human Fertilisation and Embryology Authority is in the process of approving the use of mitochondrial transfer from a third-party donor in the case of mitochondrial disease. A modification of this technique is the use of autologous germline mitochondrial energy transfer (AUGMENT; OvaScience), which acts a bit like putting a new battery in an old car, and may make older eggs more fertile. 
We have come a long way in reproductive medicine during the past 40 years, and I cannot even imagine where the next 40 years will take us.

Competing interests: I am a shareholder in Monash IVF.

Provenance: Commissioned; externally peer reviewed.

1 de Kretzer D, Dennis P, Hudson B, et al. Transfer of a human zygote. Lancet 1973; ii: 728-729.

2 Steptoe PC, Edwards RG. Birth after the reimplantation of a human embryo. Lancet 1978; ii: 366.

3 Lopata A, Johnston IW, Hoult IJ, Speirs Al. Pregnancy following intrauterine implantation of an embryo obtained by in vitro fertilization of a preovulatory egg. Fertil Steril 1980; 33: 117-120.

4 Wood C, Trounson A, Leeton J, et al. A clinical assessment of nine pregnancies obtained by in vitro fertilization and embryo tranfer. Fertil Steril 1981; 35: 502-508.

5 Trounson AO, Leeton JF, Wood C, et al. Pregnancies in humans by fertilization in vitro and embryo transfer in the controlled ovulatory cycle. Science 1981; 212: 681-682.

6 Trounson A, Mohr L. Human pregnancy following cryopreservation, thawing and transfer of an eight-cell embryo. Nature 1983; 305: 707-709.

7 Trounson A, Leeton J, Besanko M, et al. Pregnancy established in an infertile patient after transfer of a donated embryo fertilised in vitro. Br Med J (Clin Res Ed) 1983; 286: 835-838.

8 Trounson A, Anderiesz C, Jones G. Maturation of human oocytes in vitro and their developmental competence. Reproduction 2001; 121: 51-75.
9 Jones GM, Trounson AO, Gardner DK, et al, Evolution of a culture protocol for successful blastocyst development and pregnancy. Hum Reprod 1998; 13: 169-177.

10 Trounson AO, Leeton JF, Wood C, et al. The investigation of idiopathic infertility by in vitro fertilization. Fertil Steril 1980; 34: 431-438.

11 Yates CA, Thomas C, Kovacs GT, de Kretser DM. Andrology, male factor infertility and IVF. In: Wood C, Trounson A, editors. Clinical in vitro fertilization. 2nd ed. London: Springer-Verlag, 1989: 95-111.

12 Nelson SM, Yates RW, Lyall H, et al. Anti-Müllerian hormone-based approach to controlled ovarian stimulation for assisted conception. Hum Reprod 2009; 24: 867-875.

13 Kovacs GT, King C, Cameron I, et al. A comparison of vaginal ultrasonicguided and laparoscopic retrieval of occytes for in vitro fertilization. Asia Oceania J Obstet Gynaecol 1990; 16: 39-43.

14 Potdar N, Gelbaya TA, Nardo LG. Oocyte vitrification in the 21st century and post-warming fertility outcomes: a systematic review and meta-analysis. Reprod Biomed Online 2014; 29: 159-176.

15 Kovacs GT, Breheny S, Maclachlan V, et al. Outcome of pregnancies achieved by in vitro fertilisation techniques and diagnosed as twins at the 6 week ultrasound. Aust N Z J Obstet Gynaecol 2004; 44: 510-513.

16 Wang YA, Kovacs G, Sullivan EA. Transfer of a selected single blastocyst optimizes the chance of a healthy term baby: a retrospective population based study in Australia 2004-2007. Hum Reprod 2010; 25: 1996-2005.

17 Burmeister L, Kovacs GT, Osianlis T. First Australian pregnancy after ovarian tissue cryopreservation and subsequent autotransplantation. Med J Aust 2013; 198: 158-159.

18 Stern CJ, Gook D, Hale LG, et al. Delivery of twins following heterotopic grafting of frozen-thawed ovarian tissue. Hum Reprod 2014; 29: 1828. 